\title{
Violence, Harassment, and Bullying at Work: How Does the Australian Rail Industry Compare and What Can Be Done?
}

\author{
Kristin van Barneveld, University of Sydney and Australian Rail, \\ Tram and Bus Industry Union \\ Roger Jowett, Australian Rail, Tram and Bus Industry Union
}

\begin{abstract}
"Frontline employees are becoming scapegoats for late trains, delayed flights, bewildered people, long queues and cuts to services. Staff have been punched, kicked, bitten and spat on by people who are overwrought, strung out on alcohol or drugs, mentally unstable or just plain angry at the world" (Robinson 2004).
\end{abstract}

Violence in the workplace is becoming an increasingly important issue. Violence can take a number of forms including physical, verbal and nonverbal communication, intimidation and bullying, exclusion, sexual harassment, and stalking. In the rail industry, workers can be exposed to direct attacks, witnessing attacks on passengers, and suicides, in addition to accidents involving coworkers and/or members of the general public. 
This article draws from the Australian experience to highlight the risks posed to rail workers by workplace violence, harassment, and bullying. It is suggested that further research is required in the rail industry to identify the extent of these issues. Further, it is proposed that violence in railway workplaces needs to be unambiguously recognized as an occupational health and safety issue, rather than being treated as an external (police) responsibility. This article proposes a number of responses to reduce the exposure of rail industry workers to workplace violence. This includes the development of codes of conduct and agreements among employers, employees and their unions, and recognition that cooperation is crucial in developing responses to violence in railway workplaces.

\section{Introduction}

Although not a new issue, addressing violence, harassment, and bullying in workplaces is becoming increasingly important, particularly since the attacks on New York in September 2001 and the Madrid bombings in March 2004. In addition to steps designed to reduce the likelihood of further terrorist attacks, in public transport there also has been a focus on measures to address other sources of violence, bullying and harassment-these include shortages of skilled labor, privatization and managerial change.

While workplace violence, harassment, and bullying have featured strongly in the international literature, until recently there has been only limited discussion about these concerns in Australian workplaces. Furthermore, although an increasing amount of literature, both in Australia and overseas, contains information about workplace violence in other industries, there is little empirical evidence available about workplace violence, bullying, and harassment in the rail industry.

This article draws from the extant literature about workplace violence, harassment, and bullying both in the economy more broadly and in the transport industry specifically. Although the focus of this article is on the Australian rail experience, the lack of evidence is such that some information from overseas and from other industries also is included. The multi-faceted approach used here serves to highlight the types of problems faced by workers, unions, management, and government operating within the rail industry. The experiences outlined in the article assist in the development of suggested options to address these concerns.

The article first briefly defines what constitutes violence, harassment, and bullying in a workplace context. Second, various sources of violence, harassment, and bul- 
lying are explored. It is suggested that, in the rail industry, workers are potentially exposed to many forms of workplace violence, in particular that which arises from working alone, working irregular hours, working with the public, and working with valuables or money. Declining service standards, and the consequent public frustration over waiting times and poor service has exacerbated anger among transport users. This anger translates into violence and harassment against rail workers.

The second section of the paper outlines experiences from members of the Australian Rail, Tram and Bus Industry Union (RTBU). This material was collected during interviews in September 2004. Third, the consequences for workers, government, and employers are explored, with particular reference to two cases. The first, where a joinery company and its directors were fined $\$ 45,000$ for failing to ensure that a workplace was free from bullying, and the second, where a $\$ 50,000$ fine was imposed on Ballarat Radio Pty Ltd. for failing to address bullying. Both cases provide lessons for employers on how best to manage workplace violence and the consequences of ignoring such behavior, and both focus on employer failure to provide a safe workplace under occupational health and safety legislation, obligations that are discussed in the fourth section of the article. The final section details possible policy responses to the problem of increasing workplace violence, harassment, and bullying in the rail industry before some concluding comments are made.

\section{Definitions}

Violence is broadly defined as "a perceived or actual verbal or emotional threat or physical attack on an individual's person or property by another individual, group or organization." Violence can take a number of forms, including physical acts, abusive verbal and nonverbal communication, intimidation and bullying, exclusion, sexual harassment, and stalking (ITF 2003:A1, taken from Essenberg 2003). In a workplace context, violence and harassment have been defined as "incidents where persons are abused, threatened or assaulted in circumstances related to their work, involving an explicit or implicit challenge to their safety, well-being and health" (Wynne et al. 1997, in Eurofound 2004:2).

Bullying or psychological violence is defined by the World Health Organization as the "intentional use of power against another person or group that can result in harm to physical, mental, spiritual, moral or social development" (Eurofound 2004:3). Bullying is generally considered to be behavior that is systematically 
repeated rather than a single incident (Vartia 2002; Thomas 2004), and is typified by a power imbalance either caused by organizational factors (i.e., supervisor/ employee) or by previous incidents of bullying or interpersonal conflict. Although bullying is generally regarded as conflict between employees and/or management, it also can be caused by parties external to the workplace. In the Australian context, bullying has been widely defined by the New South Wales Labor Council as "repeated, unreasonable behavior directed toward an employee, or group of employees that creates risk to health and safety" (Labor Council 2004b:1).

As well as having different forms, workplace violence and harassment can come from a wide number of sources including customers, passengers, management, and colleagues. These sources have been variously referred to as external violence, service-related violence, internal violence, and organizational violence. Each is discussed below in the context of the rail industry.

\section{External Violence}

External violence is defined as acts done by intruders to an organization who have no legitimate relationship with the organization. In the rail industry, this includes vandalism and other acts of trespass onto railway property. In recent years, external violence has been exacerbated by technological change. As automatic ticket machines, computers, video cameras, and other automated systems have replaced workers on stations and on trains, "potential troublemakers have fewer uniformed staff watching them and, when trouble does break out, there are fewer employees available to deal with the problem or to alert the police" (ILO 2003).

\section{Service-Related Violence}

Service-related violence refers to "aggressive acts by customers" and can be used to describe the type of violence perpetrated against workers in the rail industry by passengers. This violence typically derives from those whose behavior is erratic (due to, for example, mental illness or intoxication) and from public frustration over waiting times and poor service (ILO 2003).

\section{Internal Violence}

Internal violence describes acts done by management, employees, former employees, or those with an employment-based connection to the workplace. This includes bullying. Internal violence can take many forms including:

- slander, gossip and rumors,

- social isolation, 
- continuous criticism of an employee's work and its results,

- threats or acts of physical violence,

- insinuations about a person's mental state (Vartia 2002:22),

- being required to perform work tasks without proper training or instruction,

- unreasonable overtime, unfair rostering, unfair allocation of work or being asked to perform nonwork related activities,

- excessive supervision,

- damage or interference with personal belongings, sabotage, or undermining of work,

- use of loud, abusive, threatening, or derogatory language, particularly in front of other workers,

- threat (explicit or implied) of termination of employment; and

- inappropriate use of performance management tools (Labor Council 2004b).

\section{Organizational Violence}

Organizational violence occurs when employees are placed in dangerous or violent situations or when long-term workplace bullying or harassment is not addressed (Essenberg 2003:7). Specific situations that may enhance the risk of exposure to organizational violence include working alone, working with the public, and working with valuables or money (ITF 2003:A4). Certainly for rail workers, the effects of violence can be compounded because of work location. For example, train guards, on-board services staff, locomotive drivers, and station staff often work alone and cannot necessarily easily escape a violent situation (ILO 2003; ITF 2003).

The triggers and causes of all forms of workplace violence (service-related, internal, external and organizational), are, according to the ILO, "controlled and exacerbated by management policy." It has been argued that with the pressures of privatization and corporatization, management policy has become focused on profit, to the detriment of occupational health and safety (Essenberg 2003:8). However, there are examples to illustrate that organizations are increasingly introducing initiatives designed to address workplace violence. For example, in Australia the rail and police unions have publicly campaigned for increased staffing of train stations. In 2003, 130 of 209 stations in Melbourne were unstaffed (Parris 2003:25). By September 2004, 30 of the 130 stations had become permanently staffed. An 
additional 20 stations had become staffed during the afternoon peak period, and 100 additional workers had been employed to patrol both trains and the remaining unstaffed stations. This increased staffing measures addressed several sources of workplace violence, particularly external and organizational violence.

\section{Evidence of Workplace Violence, Harassment, and Bullying}

While workplace violence, harassment, and bullying have been clearly defined above, what is yet unclear is the incidence of these types of violence. This section provides evidence of workplace violence, harassment, and bullying in Australia, with a particular focus on the rail industry. This section reviews evidence from previous studies and also draws from interviews with rail workers conducted in September 2004. The examples provided by workers are particularly useful in highlighting the problem in the rail industry and in developing policy responses to workplace violence, harassment, and bullying, which are detailed later in this article.

In Australia, the rail industry has been typified by a high proportion of male employment, with female workers comprising only 10 percent of the railway workforce in 2004. Most female railway workers are employed in traditionally "female" occupations such as administration. Gender-based, internal bullying has increased as female workers have been employed in roles that were traditionally viewed as "male." Despite this, there is little empirical evidence of the incidence of workplace violence, harassment, and bullying, gender-based or otherwise.

Recently however, the peak trade union body, the Australian Council of Trade Unions (ACTU), the State Trades and Labor Councils, and individual unions began campaigning against all forms of workplace violence and gathering data as to its extent. Some have moved beyond data collection and developed Workplace Charters to address the issue. The charters are designed for employers to sign and display in their workplace to demonstrate their commitment to a workplace that provides dignity and respect to all employees. They state employer responsibilities and employee rights under occupational health and safety legislation and outline steps to promote a bully-free workplace. These steps include workplace consultation, workplace awareness campaigns, training and development, procedures to deal with complaints and, consultation and feedback. 


\section{Workplace Violence}

As suggested above, in Australia at present, data on incidence of workplace violence is very limited. Consequently, the most useful information is contained in overall crime statistics. However, it is important to note that these include all forms of violence, not just that perpetrated against rail workers. Unfortunately, crime statistics for particular industry subsectors are not published, although some unpublished data are available on request. Given this, it is difficult to obtain time series of industry-specific data, with usually only the current statistics available.

Mindful of the caveats, the most recent data show that violence on the railways is of concern. Unpublished data from the NSW Bureau of Crime Statistics and Research indicate that in the 12 months to the end of June 2004, there were 4,179 reported instances of assault, sexual offenses, robbery, stealing from a person, or malicious damage on railway premises (which include stations, rail buildings, railway sidings, railway terminals, and railway car parks). Of those offenses, 1,328 were assaults on a train or railway premises and 1,207 were stealing from a person who was either on a train or railway premises (BCSR 2004). While many of these acts may not directly involve rail workers, there is certainly a chance that rail workers may witness a number of these acts, or be required to deal with the aftermath.

To supplement the scarce data, interviews were conducted in September 2004 with rail union officials and workers. These highlight that workplace violence is a very real problem for Australian railway workers.

Workplace Violence: Australian Rail Workers Experiences

"On a daily basis, train guard members are spat on, especially more recently because of crew shortages; station staff are continually shoved and spat at."

-President, Rail Operations Division, RTBU NSW Branch

“I've been a guard for 25 years and have experienced violence numerous times. It used to be only late on a Thursday and Friday night, taking the drunks home, but now it can happen any time.... I've had beer bottles thrown at me, been threatened, spat on, I've had to break up knife fights on the train.... It used to only be the drunks but the young ones are a lot more violent now." 
"I've been doing it for a long time. Putting up with workplace violence is part of the job, but it shouldn't be."

-Train Guard

"I've seen situations where people have spat at guards when they have shut the door as the train is departing (and the offender misses the train). We regularly get abused through the train control room window by people who have missed their train or when the indicators are wrong. They bang on the window and ask you to step outside so they can either abuse you more or assault you. They are normally drunk."

—Customer Service Attendant

"I have been a Transit Officer for about 18 months. There is a lot of abuse in the job. In many instances, the abuse is verbal, and most people can be talked down in these cases. When it goes to pushing and shoving, most people stop when they are threatened with arrest. I have had my ankle broken during an arrest. We were removing a drunken male off a train and a scuffle broke out when his girlfriend got involved. During the push and shove, everyone landed on my ankle and it snapped."

-Transit Officer

"Last week I had an incident with two men on a train involving a ticketing offense. After getting off the train, one man, who I went to arrest, pushed me out of the way, towards the track. My partner caught me, just in time by the arm as I fell towards the track. It is a blokey environment but generally there is not much abuse between coworkers, it mainly comes from passengers. Workplace violence is part of the job but it is not acceptable by any standard."

-Transit Officer

\section{Bullying}

While data enumerating workplace violence are limited, there is an increasing interest in the impact of bullying at the workplace and, consequently, data on the incidence of bullying is becoming more common. For example, a range of studies have asked workers whether they have observed someone at their workplace being exposed to bullying. These studies estimate that between 30 and 70 percent of employees have observed instances of bullying (Vartia 2002:19). More precisely, the European Union has estimated that 9 percent of the workforce each year is 
subject to bullying, but underreporting means that the incidence of bullying could be much higher. Some studies estimate as high as 38 percent of the workforce is subject to bullying in any year (Marles 2003).

In Australia, the ACTU has estimated that "350,000 workers are subjected to longterm bullying ... while 2.5 million experience some aspect of bullying over the course of their working lives" (ACTU 2003b). The Labor Council of NSW puts the figure somewhat higher, with its survey conducted in 2004 finding that 74 percent of workers had experienced bullying at their workplace during their working life (Labor Council 2004a).

A survey conducted by the ACTU in 2000 identified that almost 70 percent of employees who were bullied had been bullied by a manager or supervisor (Marles 2003). Further, 54 percent of workers believed that their workplace had a bullying culture (Labor Council 2004a). The key ways in which workers felt bullying was manifested were intimidation, threatening behavior, harassment, pressure, abuse of power, and isolation. Interestingly, in 44 percent of cases, workers had taken time off work due to bullying, but, in only 4 percent of cases, a workers' compensation claim had been made.

Bullying is increasingly becoming recognized as a problem in the Australian rail industry. At a 2004 Women's Conference held by the rail union, significant discussion centered on bullying. The Human Resource Manager for a large suburban rail passenger transport provider, RailCorp, flagged bullying as a key issue for the future. She recognized that a response was needed, particularly given the examples provided by women workers.

Workplace Bullying: Australian Rail Workers Experiences

The quotes below suggest that bullying in the Australian rail industry is restricted to gender-based attacks and that it comes from both coworkers and management. The quotes also suggest that, until recently, both workers and employers have done little to address the issues, but there is an increasing recognition by rail organizations that the consequences from workplace violence, bullying, and harassment are too important (and too costly) to ignore.

"I started my holidays in early July, and had only been away one or two days when another female driver found an A4 piece of paper which I had put up on the noticeboard advertising a retirement dinner for one of the drivers. Someone had crossed my name off it and (written something to the effect 
that I was of easy virtue).... Then about one week later, a photograph of me turned up with the same thing written on it. I know who it is and at first I thought "forget about it" but then I became really distressed. So I reported it to the employer and said I wanted it taken further. I really didn't want to go back to work after my leave but I have a mortgage so I had no choice but to go back. The issue is ongoing and I am at the point of saying that if it is not seen to adequately by management, I will take it outside to an antidiscrimination board.

Also quite recently, I was asked to help someone from a completely different department who had been sexually harassed. This 21-year-old woman was propositioned by a male employee and told that if she had flashed her breasts in the interview and worn a shorter skirt, she would have got the promotion. She told him that she didn't like being spoken to like that. Although she was as equally qualified as the three other people who applied for the job, she didn't get it. She still has to work in the same area as the guy who sexually harassed her.

I hear other instances of not just women but men who get bullied. It is pretty widespread and it is not something which has been squashed, it is something which is serious and ongoing."

-Female Suburban Train Driver

"Often the type of bullying that goes on comes from supervisors and management. For example, in the past we had a letter from a manager which said that there had been too many incidents in the last few months, and that if there were any more in the future, there would be job losses as retribution. Because there is a blame culture in rail, whenever management wants to change something at work, they will always remind you that the discipline code is there, and that they are not afraid to use it. They can find anything wrong with you at any time and use it to regress you, put it on your record, or give you some kind of warning - all to try to get you to do what they want you to do.

Teasing is part of the culture of working in a blokey industry like rail. You just get used to lewd and crude remarks - and it is always a judgment call as to what you are offended by." 


\section{Consequences of Workplace Violence, Harassment, and Bullying}

While estimates of the cost of bullying are difficult to make, the cost in Australia has been measured as between $\$ 3$ billion (Marles 2003) and $\$ 13$ billion a year (Queensland Bullying Taskforce 2001 figure, quoted in Thomas 2004). Even at the lower end of the scale, it is clear that the costs are significant.

The financial costs are only part of the consequences. According to the literature, the impact of fatalities, accidents, and assaults that involve workers is stress, fear, anxiety, feelings of hopelessness, guilt, and a fear of returning to work (Essenberg 2003:14). Similarly, studies suggest that workplace bullying leads to increased stress, depression, suicidal tendencies, anxiety and psychosomatic health complaints, aggressiveness, and other negative mental health symptoms, including those similar to post-traumatic stress disorder (Vartia 2002; Marles 2003; Labor Council 2004c). Physical manifestations can include stomach disorders, skin rashes, lethargy, and sleep disturbance (Labor Council 2004c). The effects of bullying are significant, with recent research finding that up to 75 percent of victims of long-term bullying developed symptoms similar to post-traumatic stress disorder (Thomas 2004). In a nonmedical sense, bullying can affect the reputation of the victim, and his/her performance of work tasks, communication with coworkers, and social life (Vartia 2002:11).

From an organizational perspective, bullying can lead to increased absenteeism levels, low levels of job performance, and high labor turnover. This can affect not only the victim but also others in the work unit (Vartia 2002; Labor Council 2004C, Thomas 2004).

\section{Employer and Government Obligations Regarding Violence, Harassment, and Bullying}

The human suffering that results from ... violence at work should not be underestimated. Employers have a legal duty to protect the health and safety of workers and this includes the risk of foreseeable violence at work and putting controls into place to protect workers from it (Malcolm David, Head of Psychological Policy at HSE quoted in Essenberg 2003:28). 
Although workplace violence, harassment, and bullying are increasingly being recognized as a problem, it is clear from the discussion thus far that there remains a lack of evidence as to the extent of the problem. This stems from a number of factors, including inadequate reporting mechanisms and a perceived lack of requirement by employers and workers to report incidents. The first step to eliminating workplace violence, harassment, and bullying is to quantify the extent of the problem. In the rail Australian industry, this could be achieved by legislative amendments to require all incidents of workplace violence to be notifiable occurrences under rail safety or occupational health and safety legislation. For example, each instance would be reportable to the relevant Rail Regulator, the body responsible for licensing rail operators or to the government department responsible for monitoring workplace health and safety.

Sometimes employers assume that workplace violence is the responsibility of police. This reliance on external controls possibly stems from the fact that, besides the criminal law that deals with offenses such as assault, there is no specific legislation in Australia that directly addresses workplace bullying, harassment, and violence. However, there is a range of legislative requirements that make unlawful behavior that offends, humiliates, or intimidates someone, or puts their health, safety, or welfare (including psychological) at risk (Labor Council 2004d).

Most importantly, and as suggested by the quote at the start of this section, health and safety legislation is generally broad enough to include employer responsibility to minimize exposure to risk of bullying, abuse, and assault by workmates and the general public. In Australia, the way in which workplace violence, bullying, and harassment are addressed in legislation varies. Generally, however, the objectives of the legislation state that the aim is to "promote a safe and healthy environment for people at work that protects them from injury and illness and that is adapted to their physiological and psychological needs" (NSW Occupational Health and Safety Act 2000, s3(c)). Workplace violence is specifically mentioned in Occupational Health and Safety Regulation 2001, which requires employers to identify hazards that may arise from "the potential for workplace violence" (s9(j)). Further, under the health and safety legislative requirements, employers "must remove risks from the workplace that may cause harm or injury to workers. This includes workplace violence, bullying, and harassment that expose employees to health or safety risks. It also includes taking practical steps to identify, assess and control reasonably foreseeable psychological risks" (Labor Council 2004d). 
Australian courts recently have demonstrated a willingness to apply the definitions above to encompass an employer obligation to eliminate workplace violence and bullying. While not in the rail industry, two recent cases illustrate the tough approach taken by the Australian courts to the issue of workplace violence, bullying, and harassment. The first case involved the "initiation" of a 16-year-old laborer at a joinery factory.

Five coworkers "used a cling-wrapping machine to wrap him from his feet to his neck. They secured him to a trolley and pushed it to the edge of an access penetration (which was) 4.2 meters above ground level. The workers proceeded to shove sawdust and glue into the mouth of the laborer, who was asthmatic and become unable to breathe. The workers continued to squirt glue and a fire hose into his mouth, with the entire incident lasting about half an hour until a contracted site foreman cut the laborer free" (Gadens Lawyers 2004).

Of the employees, one was fined $\$ 500$, and the remainder received 12-month good behavior bonds. In handing down a $\$ 24,000$ fine for the company and a $\$ 1,000$ fine to each of the directors, the Chief Industrial Magistrate noted that "what started out as a simple episode of bullying got out of control, leading to serious physical threat to the worker's health and safety." He stated that, while bullying is "...often seen as a bit of fun at the expense of someone else," it is "a culture that needs to be stamped out" (Gadens Lawyers 2004). On appeal, the fine for the company remained at $\$ 24,000$ but the fine for the two directors was increased from $\$ 2,000$ to $\$ 21,000$. In increasing the fine as "a deterrent," the Appeal Court said it must be made abundantly clear that the duties of employers under the occupational health and safety legislation extended to protecting employees from bullying and violence.

The second example is found in an unpublished decision of the Victorian Magistrates Court. In this case, "WorkSafe Victoria claimed that between February 2000 and October 2003, an announcer at the station had verbally and physically abused other employees" (Workplace Express 2004). In August 2004, Ballarat Radio Pty $L t d$. was fined " $\$ 50,000$ for failing to provide a safe workplace and failing to provide instruction, training and supervision on bullying" (Workplace Express 2004). In the case, Magistrate Coburn "found the company had no system in place for complaints to be made and dealt with and should have stopped the bullying when they became aware of it." Victorian WorkSafe Director John Merritt commented, "...the decision showed the courts perceived that psychological bullying 
was as unacceptable as physical bullying ... and there are consequences for failing to manage it" (WorkCover Victoria 2004).

In addition to obligations under occupational health and safety legislation, other legislation also provides redress for employees, particularly if the harassment is related to one of the grounds prohibited under legislation, such as age, sexual preference, political opinion, social origin, medical records, criminal record, trade union activities, and religion (Human Rights and Equal Opportunity Commission Act 1986); race, color and nationality (Racial Discrimination Act 1975); sex, marital status and pregnancy (Sex Discrimination Act 1984); and, disability and impairment (Disability Discrimination Act 1992).

Further, employees in Australia can access workers' compensation for physical or psychological injury that results from stress-related causes-this includes workplace violence or bullying. Importantly, under legislation such as the NSW Workers Compensation and Injury Management Act 2000, the workplace need not be the dominant cause of the psychological injury. In other words, compensation is available if workplace violence, harassment, or bullying contributes to or aggravates an existing injury (Labor Council 2004d). However, despite these broad provisions, the data presented earlier suggest that workers' compensation for stress and injury related to workplace violence and bullying is rarely accessed (Marles 2003).

It is interesting to note that, while in the United States, legislation has been passed both on a national and regional level that imposes severe penalties on persons who engage in acts of aggression against transportation workers (State of New Jersey/U.S. Patriot Act), in Australia, the focus remains on addressing the issue through existing safety and other legislation.

\section{Recommendations and Guidelines for Policy}

According to the International Transport Workers' Federation (ITF), the challenge is to alter workplace culture so that violence at work becomes considered an unacceptable practice rather than a serious problem affecting just a minority (ITF 2003:3). In Australia, WorkCover ${ }^{1}$ has recognized the need for increased awareness that workplace violence and bullying are an unacceptable problem and has highlighted the need for appropriate training to help raise awareness of the issues (Thomas 2004). Training in workplace violence, bullying and harassment could be covered as part of a worker's induction to an organization, or, for existing workers, as part of ongoing training. Such training would assist in changing the culture in 
the rail industry to one where violence, harassment, and bullying, are held to be unacceptable.

In addition to training, there are a number of ways that workplace violence, harassment, and bullying can be addressed in the rail industry:

- First, there is a need for more research to be conducted to identify the extent of violence, bullying, and harassment. This could be achieved by requiring, under rail safety and/or occupational health and safety legislation, incidents of workplace violence to be "notifiable occurrences."

- A key role can be played by occupational health and safety committees in both monitoring the incidence of these events and ensuring that adequate information is available to workers about the unacceptability of workplace violence, harassment, and bullying. Health and safety committees also can encourage the reporting of incidents and hence facilitate better data collection.

- Occupational health and safety and rail safety legislations need to be strengthened to recognize explicitly the obligations of employers and workers to eliminate workplace violence, harassment, and bullying.

- Finally, reflecting this increased focus on workplace violence and bullying, the ILO released a Code of Practice on Workplace Violence in Services Sectors and Measures to Combat this Phenomenon in August 2004. As the name suggests, the code is designed to provide general guidance to government, workers and their representatives, employers, and other concerned stakeholders in addressing the problem of workplace violence in the service sectors. The code addresses key action areas including:

- policy,

- hazard identification,

- risk assessment,

- prevention and control,

- training,

- management and mitigation of the impact,

- care and support of workers affected, and

- monitoring and evaluation. 
This code could be adapted to suit the Australian rail industry through consultation between unions, government, and employers and will take the rail industry one step closer to reducing or even eliminating workplace violence, bullying, and harassment.

\section{Summary of Findings/Conclusions}

Workplace violence, harassment, and bullying have long been a responsibility that no one wants to accept. It is clear from the policy suggestions above that these are complicated issues that can best be addressed through significant efforts by all parties. Most clearly, in Australia, there is an increasing recognition that employer obligations to provide a safe workplace extend to include a workplace free from violence, harassment, and bullying. For employees, occupational health and safety legislation places an obligation for them to act in such a manner as not to endanger the safety of others. Developments such as workplace charters and codes of practice are positive steps that should become mandatory in workplaces if the financial, physical, and emotional costs of workplace violence, harassment, and bullying are to be avoided.

\section{Endnote}

${ }^{1}$ WorkCover NSW is a statutory authority within the Minister for Commerce's portfolio. Its primary objective is to work in partnership with the NSW community to achieve safe workplaces, effective return to work, and security for injured workers. WorkCover promotes workplace health and safety, and provides a workers compensation system for the employers and workers of NSW. 


\section{References}

ACTU. 2003b. Workers' Helpline Reaching Out to New Employees. ACTU News 20. http://www.actu.asn.au/public/news/1061424413_30605.html, date accessed September 22, 2004.

BCSR. 2004. NSW Monthly Recorded Crime Statistics January 2002 to June 2004. NSW Bureau of Crime Statistics and Research, Sydney.

Essenberg, B. 2003. Violence and stress at work in the transport sector. Sectoral Activities Program Working Paper 205. International Labour Office, Geneva.

Eurofound. 2004. Violence, bullying and harassment in the workplace. European Foundation for the Improvement of Living and Working Conditions, Dublin.

Gadens Lawyers. 2004. Bullying in the workplace. National workplace relations update, August.

ILO. 2003. Transport: Sector-specific information on violence and stress, http:// www.ilo.org, date accessed, June 8, 2004.

ITF. 2003. Urban Transport Committee Meeting: Agenda Item 2: Violence at Work, International Transport Workers' Federation. London: November 19 and 20.

Labor Council. 2004a. Results of UnionSafe survey on workplace bullying. Presented at Labor Council of NSW Conference, September 8, Sydney.

Labor Council. 2004b. Bullying Fact Sheet 1-What Is Bullying? Labor Council of NSW, Sydney.

Labor Council. 2004c. Bullying Fact Sheet 2-The Effects of Bullying? Labor Council of NSW, Sydney.

Labor Council. 2004d. Bullying Fact Sheet 5-Is Bullying Legal? Labor Council of NSW, Sydney.

Marles, R. 2003. Occupational bullying in Australia. Speech by the Assistant Secretary of the ACTU to the LHMU Bullying and Harassment Seminar, Holmesglen TAFE, Moorabbin, November 12, Victoria.

Parris, K. 2003. Measure for measure. Transport International 4: 23-25.

Robinson, P. 2004. Violence at work all the rage. The Age (Saturday May 29), Victoria. 
Thomas, J. 2004. Preventing workplace bullying, WorkCover NSW Presentation to NSW Labor Council Conference on Workplace Bullying. Sydney: September 8.

Vartia, M. 2002. Workplace bullying-A study on the work environment, wellbeing and health. People and Work Research Reports 56. Finnish Institute of Occupational Health, Helsinki, December.

Workplace Express. 2004. $\$ 50,000$ OHS fine for employer for workplace bullying. August 16, www.workplaceexpress.com.au.

WorkCover Victoria. 2004. Landmark court decision sees radio station convicted and fined \$50,000 over bullying. August 13, 2004.

\section{About the Authors}

KRISTIN VAN BARNEVELD (kvanbarneveld@rtbu-nat.asn.au) joined the Australian Rail Tram and Bus Industry Union as national industrial officer in June 2003 after working at acirrt, University of Sydney in a research role since 1996. She remains an honorary research associate of acirrt. Dr. van Barneveld completed a Master of Labor Law and Relations in 1996 and completed her doctoral thesis in August 2004 at the University of Newcastle. Her doctoral thesis analyzes the use of individual employment contracts and their impact on both organizational efficiency and equitable outcomes for employees.

ROGER JOWETT (rogerjowett@bigpond.com) was national secretary of the Australian Rail Tram and Bus Industry Union until his retirement in February 2005. The RTBU was formed in 1993 as an amalgamation of four public transport unions. The RTBU is the major rail union in Australia with 60 percent of coverage of the industry. Prior to the amalgamation, Mr. Jowett was secretary of the Australian Railways Union, having been first elected as an official in 1983. 